Salvianolic acid A ameliorates the integrity of blood-spinal cord barrier via miR-101/Cul3/Nrf2/HO-1 signaling pathway

De-shui $\mathrm{Yu}^{1}$, Yan-song $\mathrm{Wang}^{1}$, Yun-long $\mathrm{Bi}^{1}$, Zhan-peng Guo ${ }^{1}$, Ya-jiang Yuan ${ }^{1}$, Song-ming Tong ${ }^{1}$, Rui-chao $\mathrm{Su}^{1}, \mathrm{Li}$-hao Ge ${ }^{1}$, Jian Wang ${ }^{1}$, Ya-li Pan ${ }^{2}$, Ting-ting Guan ${ }^{2}$, Yang Cao ${ }^{1 *}$ 


\title{
Salvianolic acid A ameliorates the integrity of blood-spinal cord barrier via miR-101/Cul3/Nrf2/HO-1 signaling pathway
}

\begin{abstract}
Salvianolic acid A (Sal A), a bioactive compound isolated from the Chinese medicinal herb Danshen, is used for the prevention and treatment of cardiovascular diseases. However, the protective function of Sal A on preserving the role of blood-spinal cord barrier (BSCB) after spinal cord injury (SCI) is unclear. The present study investigated the effects and mechanisms of Sal A $(2.5,5,10 \mathrm{mg} / \mathrm{kg}$, i.p.) on BSCB permeability at different time-points after compressive SCI in rats. Compared to the SCI group, treatment with Sal A decreased the content of the Evans blue in the spinal cord tissue at $24 \mathrm{~h}$ post-SCI. The expression levels of tight junction proteins and HO-1 were remarkably increased, and that of p-caveolin-1 protein was greatly decreased after SCI Sal A. The effect of Sal A on the expression level of ZO-1, occluding, and p-caveolin-1 after SCI was blocked by the HO-1 inhibitor, zinc protoporphyrin IX (ZnPP). Also, Sal A inhibited the level of apoptosis-related proteins and improved the motor function until 21 days after SCI. In addition, Sal A significantly increased the expression of microRNA-101 (miR-101) in the RBMECs under hypoxia. AntagomiR-101 markedly increased the RBMECs permeability and the expression of the Cul3 protein by targeting with 3'-UTR of its mRNA. The expression of nuclear factor erythroid 2-related factor 2 (Nrf2) and HO-1 was significantly increased after agomiR-101 treatment. Therefore, Sal A could improve the recovery of neurological function after SCI, which could be correlated with the repair of BSCB integrity by the miR-101/Cul3/Nrf2/HO-1 signaling pathway.
\end{abstract}

Keywords: Salvianolic acid A ; Spinal cord injury; Blood-spinal cord barrier; Tight junction; Heme oxygenase-1

\section{Introduction}

Spinal cord injury (SCI) is a devastating neurological disorder and comprises of a primary mechanical injury and a secondary injury caused by oxidative stress, immune dysfunction, and apoptosis (Silva et al., 2014). The previous studies have 
demonstrated that the maintenance of blood-spinal cord barrier (BSCB) integrity plays a major role in the recovery of neurological function after spinal cord injury (Zhou et al., 2016) and amyotrophic lateral sclerosis (Winkler et al., 2014). Therefore, therapeutics aiming to target the spinal vasculature after SCI are pivotal in the development of effective interventions for SCI (Figley et al., 2014).

Most traditional Chinese drugs have particular therapeutic advantages, thereby attracting intense attention in the field of SCI treatment (Zhang et al., 2016). The dried root of Salvia miltiorrhiza Bunge (Danshen) is a prevalent traditional Chinese medicine and has been widely used for the treatment of various diseases including cerebrovascular diseases, coronary artery diseases, and myocardial infarction (Lin et al., 2012; Zeng et al., 2013; Ai et al., 2015). Salvianolic acids are the most abundant water-soluble compounds extracted from Danshen, especially, salvianolic acid A (Sal A) and salvianolic acid B (Sal B) that have been found to possess potent anti-oxidative abilities due to their polyphenolic structure. Sal A was demonstrated as the most potent antioxidant among the salvianolic acids, whereas Sal B was speculated to offer maximum commercial value for food and medicinal purposes owing to its abundance in Danshen (Sun et al., 2009). Sal A is a multi-target agent and with various pharmacological activities, including antioxidation, anti-apoptosis, and the prevention of diabetic complications (Wang et al., 2016; Xie et al., 2015; Qiang et al., 2014). Sal A is a novel matrix metalloproteinase-9 inhibitor that prevents cardiac remodeling in spontaneously hypertensive rats (Teng et al., 2016) and improves the impaired memory function induced by cerebral ischemia-reperfusion (Wang et al.,

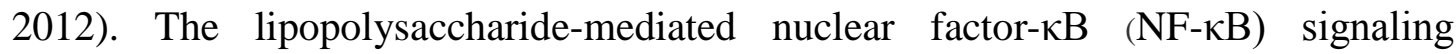
pathway could be suppressed by Sal A by targeting IKK $\beta$ (Oh et al., 2011). In the previous study, we found that Sal B promoted the recovery of neurological function after SCI, which was related to the repair of the damaged BSCB (Fan et al., 2013). However, the effects and mechanisms of Sal A on BSCB dysfunction induced by SCI are yet ill-understood.

Based on the studies mentioned above, we utilized a compressive SCI model in rats and investigated the effects and mechanisms of Sal A on BSCB permeability and 
motor dysfunction induced by SCI.

\section{Results}

\subsection{Effect of Sal A on the BSCB permeability in rats after SCI}

The content of Evans blue (EB) in the injured spinal cord tissue was evaluated at different time-points after compression injury. The EB content of the spinal cord tissue at days 1,7 , and 21 after SCI was $4.8 \pm 0.4,3.8 \pm 0.5$, and $2.4 \pm 0.2$, respectively. The EB content was $3.5 \pm 0.3,2.6 \pm 0.2$, and $2.2 \pm 0.2$ in the $5 \mathrm{mg} / \mathrm{kg}$ Sal A group on days 1, 3, day 7, respectively, after SCI. In the $10 \mathrm{mg} / \mathrm{kg}$ Sal A group, the EB content was $3.3 \pm 0.3,2.5 \pm 0.1$, and $2.3 \pm 0.3$, respectively. The EB content in spinal cord tissue was significantly decreased by Sal A (5 and $10 \mathrm{mg} / \mathrm{kg}$ ) treatment, which was significantly reversed by Znpp (Fig. $1,{ }^{*} p<0.05$ vs. Sal A group). Thus, the dosage of $5 \mathrm{mg} / \mathrm{kg}$ is optimal and was selected for the subsequent experiments.

\subsection{Effects of Sal A on the expression of tight junction (TJ) protein and} p-caveolin-1 protein in the injured spinal cord tissue

The upregulation of p-caveolin-1 and downregulation of TJ protein expressions was observed at $24 \mathrm{~h}$ after SCI, which was significantly reversed by Sal A (Fig. 2A). The integrated density value (IDV) ratios of p-caveolin-1 in Western blot analyzed at $24 \mathrm{~h}$ post-surgery was $0.25 \pm 0.03,0.7 \pm 0.04,0.34 \pm 0.03$, and $0.55 \pm 0.05$ in sham-operated, SCI, Sal A, and Znpp+Sal A groups. The IDV of p-caveolin-1 protein in the SCI group was higher than that in the sham-operated group (Fig. $2 \mathrm{~B}, * * p<0.05$ vs. sham-operated group). The IDV of ZO-1 was $0.85 \pm 0.07,0.42 \pm 0.03,0.73 \pm 0.4$, $0.51 \pm 0.5$ at $24 \mathrm{~h}$ after SCI with Sal A. The IDV of the ZO-1 $(0.42 \pm 0.03)$ and Claudin-5 $(0.35 \pm 0.02)$ protein in the SCI group was significantly lower than that in the sham-operated group $(0.85 \pm 0.07$ and $0.88 \pm 0.09)$ at $24 \mathrm{~h}$ after SCI (Fig. 2C, 2D; ${ }^{\# \#} p<0.01$ vs. SCI group). However, ZnPP blocked the protective effects of Sal A on SCI-induced changes in the expression of p-caveolin-1, ZO-1 and Claudin-5 in the injured spinal cord tissues ( ${ }^{\#} p<0.01$ vs. Sal A group).

\subsection{Effect of Sal A on the expression of HO-1 protein in SCI rats}

The IDV of HO-1 was $0.25 \pm 0.03,0.45 \pm 0.04,0.74 \pm 0.6$, and $0.53 \pm 0.5$ at $24 \mathrm{~h}$ post-surgery in the sham-operated group, SCI group, Sal A group, and Znpp+Sal A 
group, respectively. The protein levels of HO-1 at $24 \mathrm{~h}$ after SCI increased significantly $(* * p<0.05$ vs. sham-operated group), which was further potentiated by Sal A $(5 \mathrm{mg} / \mathrm{kg})$ treatment (Fig. 3A, 3B; ${ }^{\#} p<0.01$ vs. SCI group). However, the induction of HO-1 protein expression was blocked by ZnPP (Fig. 3B; $*^{\#} p<0.01$ vs. Sal A group).

\subsection{Effect of Sal A on the expression of caspase-3, Bcl-2, and Bax proteins}

The IDV of Caspase- 3 was $0.23 \pm 0.03,1.2 \pm 0.8,0.37 \pm 0.4$, and $0.58 \pm 0.5$ at $24 \mathrm{~h}$ post-surgery in the four groups. The IDV of Bcl-2 and Bax was 0.92 \pm 0.08 and $0.15 \pm 0.02$ in the sham-operated group, $0.45 \pm 0.04$ and $0.82 \pm 0.7$ in the SCI group, $0.76 \pm 0.6$ and $0.52 \pm 0.5$ in the Sal A group, and $0.58 \pm 0.6$ and $0.57 \pm 0.5$ in the Znpp+Sal A group. The expression of caspase-3 and Bax protein was significantly increased, whereas that of $\mathrm{Bcl}-2$ protein was significantly decreased compared to the sham-operated group at day 21 after SCI (**p<0.05 vs. sham-operated group), which

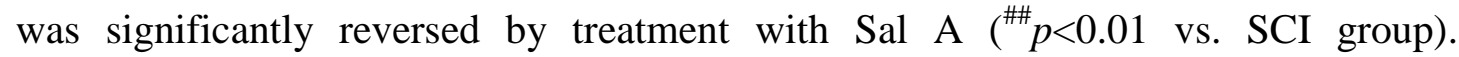
Moreover, ZnPP significantly antagonized the effect of Sal A on the expression of caspase-3, Bcl-2, and Bax proteins (Fig $4 ; *^{\#} p<0.01$ vs. Sal A group).

Fig. 5A showed that Sal A treatment increased the expression of Bcl-2 and attenuated the expression of Bax-like immunoreactivity in neurons in the gray matter of injured spinal cord tissue. The mean optical density values of Bcl-2 were higher $(0.22 \pm 0.014)$ in Sal A group than that in the control group, which was $0.16 \pm 0.01\left({ }^{*} p<0.05\right.$; Fig. 5C). On the other hand, the mean optical density values of Bax expression were $0.18 \pm 0.015$ and $0.26 \pm 0.02$ in Sal A and SCI groups, respectively ( ${ }^{*} p<0.05$; Fig. 5D).

\subsection{Effect of Sal A on motor function of rats after SCI}

The rats subjected to SCI exhibited significant deficits in hindlimb movement. The BBB scores were $1 \pm 0.05$ and $3.8 \pm 0.03$ on day $3,4 \pm 0.04$ and $8.4 \pm 0.06$ on day 7 , $6.2 \pm 0.07$ and $11.2 \pm 0.08$ on day $10,8.4 \pm 0.08$ and $12.8 \pm 0.09$ on day $12,9 \pm 0.075$ and $13.8 \pm 0.092$ on day $14,10 \pm 0.1$ and $14.7 \pm 0.11$ on day 21 after SCI in SCI and Sal A groups, respectively. The therapy with 5 and $10 \mathrm{mg} / \mathrm{kg}$ Sal A significantly ameliorated the hindlimb motor disturbances from day 3 to day 21 post-SCI $\left(* p<0.05,{ }^{*} p<0.05\right.$ vs. 
SCI group). ZnPP significantly inhibited the improved role of Sal A on the motor function (Fig 6; ${ }^{\#}<<0.05,{ }^{\#} p<0.01$ vs. Sal A group).

2.6 Effect of Sal A and miR-101 on the permeability of RBMECs induced by hypoxia

The effects of Sal A on transendothelial electric resistance (TEER) were significantly increased in the $20 \mu \mathrm{M}$ group $(140 \pm 10)$ and $100 \mu \mathrm{M}$ group $(145 \pm 12)$ than in the 10

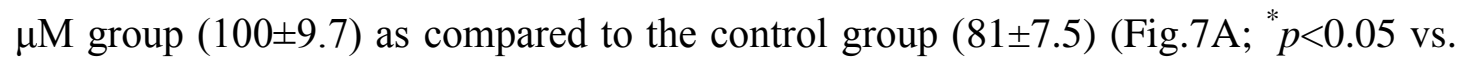
control group). $20 \mu \mathrm{M}$ Sal A dose was administrated for $24 \mathrm{~h}$ in the subsequent experiments. The TEER values in miR-101(-)+Sal A group and miR-101(-)-NC+Sal A group were $101 \pm 9.8$ and $142 \pm 11$, suggesting that antagomiR-101 significantly inhibited the effect of Sal A $(20 \mu \mathrm{M})$ on TEER (Fig. 6B; ${ }^{*} p<0.05$ vs. miR-101(-)-NC+Sal A group).

\subsection{Sal A decreased the Cul3 mRNA induced by hypoxia in RBMECs by upregulating the miR-101 expression}

As shown in Fig. 7A, the expression of the miR-101 of RBMECs was higher in Sal A group $(1.8 \pm 0.25)$ than that in the control group $(1.1 \pm 0.2)$. The mechanism-oriented investigations defined $\mathrm{Cul} 3$ as a direct and functional downstream target of miR-101 (Fig. 8B). The relative expressions of Cul3 mRNA and protein were $1 \pm 0.02$ and $0.4 \pm 0.035,0.9 \pm 0.07$ and $0.45 \pm 0.039,1.8 \pm 0.12$ and $0.7 \pm 0.05,0.95 \pm 0.0 .08$ and $0.4 \pm 0.04,0.4 \pm 0.05$ and $0.2 \pm 0.03$ in the control, miR-101(-)-NC, miR-101(-), miR-101(+)-NC, and miR-101(+) groups, respectively. The level of Cul3 mRNA and protein was reduced or elevated by overexpression or inhibition of miR-101, respectively (Fig. $8 \mathrm{C}-\mathrm{E} ; \quad * * p<0.01$ vs. miR-101(-)-NC group; ${ }^{*} p<0.05$ vs. miR-101(+)-NC group). In addition, the expressions of Nrf2 and HO-1 proteins were significantly increased by antagomiR-101 treatment (Fig. 9; $*_{p}<0.05, * * p<0.01$ vs. miR-101(-)-NC group).

\section{Discussion}

The spinal cord homeostasis is the premise and foundation to maintain the normal function of neurons in spinal cord tissue. The BSCB is a vital component in maintaining the CNS homeostasis and compromised BSCB has been associated with 
different pathologies affecting the neuronal function of the spinal cord (Echeverry et al., 2011). Early repair of BSCB is critical for the treatment of SCI. However, the previous studies focused more on the mechanism of neuronal apoptosis induced by SCI, ignoring that the improvement of the BSCB integrity plays a key role in the recovery of motor function induced by SCI. In the present study, Sal A at a dose of 5 or $10 \mathrm{mg} / \mathrm{kg}$ significantly reduced the increase in BSCB permeability at $24 \mathrm{~h}$ post-injury. However, the protective mechanism of Sal A on SCI-induced BSCB disruption necessitates further investigation.

BSCB is primarily composed of spinal cord vascular endothelial cells lacking window hole and pinocytotic vesicles, basement membrane, and astrocyte foot processes (Bartanusz et al., 2011). The delivery pathways of the drug into the spinal cord tissue through BSCB can be classified as paracellular and transcellular pathways. After SCI, the damage of TJs and an increase in the quantity of pinocytotic vesicles resulted in an increased BSCB permeability (Sharma et al., 2005). TJs are composed of complex TJ proteins including transmembrane proteins, members of the peripheral membrane protein family, and adhesion molecules (Appelboom et al., 2016). TJ dysfunction represents BSCB disruption, which is most frequently seen during SCI (Yang et al., 2016). Caveolae play a major role in endocytosis and transcytosis of various compounds. Caveolin-1 (Cav1) is the most prominent marker of caveolae in vascular endothelial cells and plays a pivotal role in regulating the permeability of BBB (Nag et al., 2009). Cav1 is an essential structural component of caveolae, and its phosphorylation by $\mathrm{Src}$ is associated with an increase in caveolae-mediated endocytosis. The increase of phosphorylated Cav-1 in the endothelium of vessels was associated with early BBB breakdown following brain injury (Nag et al., 2009). To study the effect and mechanism of Sal A on BSCB function, we examined the effects of Sal A on the expression of TJ proteins and p-caveolin-1 in the injured spinal cord. In the present study, the expression of p-caveolin-1 protein was significantly increased, and $\mathrm{TJ}$ proteins were greatly attenuated at $24 \mathrm{~h}$ after injury, which was antagonized by treatment with Sal A. Taken together, these results provide a compelling evidence that Sal A could directly promote and enhance BSCB integrity during SCI through the 
regulation of paracellular and transcellular pathways.

Heme oxygenase-1 (HO-1) is upregulated in response to oxidative stress and can catalyze the degradation of pro-oxidant heme into carbon monoxide $(\mathrm{CO})$, iron, and bilirubin (Pamplona et al., 2007). The HO-1 pathway is vital in the maintaining the $\mathrm{BBB} / \mathrm{BSCB}$ integrity against oxidative stress, and it acts in synchronization with other crucial enzymatic systems for the maintenance of cellular homeostasis (Wang et al., 2013). A previous study demonstrated that overexpression of HO-1 may improve the spinal cord function in the early stages after SCI (Kumar et al., 2016). The expression of ZO-1 and Claudin-5 was upregulated by Sal A (5 mg/kg, i.p.) treatment after SCI and this effect was blocked by ZnPP, a specific HO-1 inhibitor. An increased phosphorylation of Cav-1-Y14 could inhibit the expression of HO-1, thereby further aggravating the inflammatory response (Jin et al., 2008; Zhong et al., 2015). This suggested that Sal A could upregulate the expression of HO-1 by inhibiting the phosphorylation of caveolin-1. Recently, Lin et al. demonstrated that over-expression of HO-1 may contribute to the altered expression of salient miRNAs and their mRNA targets in CNS disorders (Lin et al., 2015). In addition, our results demonstrated that Sal A significantly ameliorated the hindlimb motor disturbances up to 21 days after SCI. Furthermore, the SCI-mediated increase in the expression of Bax and caspase-3 protein and decrease in the expression of Bcl-2 was significantly reversed by Sal A treatment, which was also antagonized by Znpp pretreatment. These results suggested that Sal A protects BSCB integrity and improves the motor dysfunction of rats via the HO-1 pathway.

Nuclear factor erythroid 2-related factor 2 (Nrf2) is known to affect cellular sensitivity levels in pathological and physiological mechanisms by interacting with the antioxidant response element (ARE) and the electrophile response element EpRE of a large number of cytoprotective gene promoters. The expression of HO-1 is regulated by the Nrf2/Keap1/Cul3/Rbx 1 E3 ligase complex, which is well-established. Cul3 binds the RING domain protein Rbx1 that, in turn, recruits an E3 ligase, which facilitates Nrf2 ubiquitination and degradation (Emanuele et al., 2011). MicroRNAs (miRNA) are endogenous regulators produced as small, nonprotein-coding RNAs, 
with 21-25 nt length, negatively regulating the gene expression at the post-transcriptional level by targeting with their 3'-UTR of mRNA. Previous studies have shown that miRNAs are important modulatory factors in the pathological development of SCI (Li et al., 2016). Moreover, siRNA-mediated knockdown of Cul3 significantly increased the Nrf2 protein levels (Loignon et al., 2009). LPS preconditioning effectively alleviates the SCI-induced impairment and preserves the nervous function in a Nrf2-dependent manner (Li et al., 2016). MiR-101 effectuates as a positive regulator of $\mathrm{HO}-1$ expression by modulating the Cul3/Nrf2 pathway (Kim et al., 2014). In the present study, we demonstrated that hypoxia elevates the expression of miR-101, which binds to the 3 'UTR of Cul3 mRNA. A reduction of Cul3 level activated the Nrf2/HO-1 signal pathway. Sal A greatly induced the upregulation of miR-101 expression in RBMECs under hypoxia treatment, suggesting that Sal A could increase the expression of HO-1 by inducing the miR-101/Cul3/Nrf2 signaling pathway.

In conclusion, our findings indicated that Sal A effectively improved the motor function and inhibited the level of apoptosis induced by SCI, at least partially, which could be correlated with the improvement of BSCB integrity. Additional studies are essential to gain insight into the potential therapeutic effect of Sal A in SCI patients.

\section{Materials and Methods}

\subsection{Animal experiments}

\subsubsection{Establishment of a compressive SCI rat model}

The adult male Sprague-Dawley rats (200-250 g, 7-8 weeks old) were purchased from the Experimental Animals Center of Liaoning Medical University. A compressive SCI rat model was established according to the previous study (Huang et al., 2007). Rats were anesthetized with $10 \%$ chloral hydrate $(3.5 \mathrm{~mL} / \mathrm{kg})$, and then the skin and muscle overlying the spinal column were incised; a laminectomy was performed at T12, leaving the dura intact. A weight of $50 \mathrm{~g}$ was applied statically to the T12 of the spinal cord for exactly $5 \mathrm{~min}$. 
Sal A (purity $>99 \%$ ) was purchased from Sigma-Aldrich and then was dissolved using normal saline containing $10 \%$ vitamin C. Rats were randomized into four groups: sham-operated group, sham surgery included general anesthesia, skin incision, and laminectomy but no dural compression; SCI group, rats were administered an intraperitoneal injection of the carrier solutions (normal saline containing $10 \%$ vitamin C) after SCI; SCI+Sal A group, the rats were administered Sal A doses of 2.5, 5, or $10 \mathrm{mg} / \mathrm{kg}$ (i.p.) at $20 \mathrm{~min}$ post-surgery and then every $24 \mathrm{~h}$ (no more than 7 days), respectively; SCI+Sal A+ZnPP group, rats, were injected $25 \mu \mathrm{mol} / \mathrm{kg}$ of Znpp (i.p.) at $2 \mathrm{~h}$ before SCI followed by Sal A (5 mg/kg, i.p.) at $20 \mathrm{~min}$ post-surgery and then every $24 \mathrm{~h}$ (no more than 7 days). Seven rats from each group were used in the subsequent experiments.

\subsubsection{Motor functional test}

The motor function of rats subjected to compressive injury was evaluated once daily until 21 days after SCI. The recovery from motor dysfunction was estimated by the modified murine Basso, Beattie, and Bresnahan (BBB) hindlimb locomotor rating scale (Basso et al., 1995).

\subsubsection{Measurement of BSCB permeability}

The BSCB permeability was quantitatively evaluated by content of Evans blue (EB) in the injured spinal cord tissue at $24 \mathrm{~h}$ after SCI. The spinal cord tissue of rats was extracted after $2 \mathrm{~h}$ following the injection of $\mathrm{EB}$ via femoral vein $(2 \% \mathrm{~EB}, 2 \mathrm{~mL} / \mathrm{kg})$. The optical density was determined with a spectrophotometer at $620 \mathrm{~nm}$. The quantitative estimation of the dye content in the spinal cord was based on the external standards solubilized in the same solvent.

\subsubsection{Western blot}

Western blot analysis was performed to investigate the ZO-1, Claudin-5, HO-1, p-caveolin-1, caspase-3, Bax, and Bcl-2 proteins in the injured spinal cord tissue at 24 $\mathrm{h}$ after SCI. Samples were centrifuged at $12000 \mathrm{~g}$ for $30 \mathrm{~min}$ at $4{ }^{\circ} \mathrm{C}$ and the soluble protein concentration was determined by the Coomassie G250 binding method. Protein lysates prepared (30 $\mu \mathrm{g} /$ lane) were resolved on 12\% SDS-polyacrylamide gels 
and transblotted. The membranes were incubated with polyclonal anti-ZO-1 (1:100, Invitrogen, Life Technology), anti-Claudin-5 (1:200, Invitrogen, Thermo fisher, USA), anti-HO-1 (1:200, Abcam, Cambridge, UK), anti-p-caveolin-1 (1:800, Cell Signaling Technology, USA), anti-caspase-3 (1:1000, Santa Cruz Technology, USA), anti-Bax (1:200, Santa Cruz Technology, USA), anti-Bcl-2 (1:200, Santa Cruz Technology, USA), and anti-Nrf2 (1:200, Thermo fisher, USA), anti-Cul3 (1:200, Thermo fisher, USA ) antibodies. The immunoreactive bands were scanned using Chemi Imager 5500 V2.03 software. The IDVs were analyzed by Fluor Chen 2.0 software and normalized against that of $\beta$-actin, which is the endogenous control.

\subsubsection{Immunohistochemistry}

The spinal cord tissue of the rats in the Sham-operated group, SCI group, SCI+Sal A group $(5 \mathrm{mg} / \mathrm{kg})$ and $\mathrm{SCI}+\mathrm{Sal} \mathrm{A}+\mathrm{ZnPP}$ group for $24 \mathrm{hr}$ groups were fixed by $4 \%$ paraformaldehyde. The sections were blocked in blocking buffer (3\% BSA) for 20 min and were incubated with the rabbit polyclonal antibody anti-Bax (diluted 1:100, Santa Cruz Technology) and anti-Bcl-2 (diluted 1:100, Santa Cruz Technology) following standard procedures. For semi-quantitative measurements of Bax and Bcl-2 density, the images were collected (IX71,Olympus, Japan) and then measured using an image analyzing system .

\subsection{In vitro experiments}

\subsubsection{Cell culture, hypoxia, and drug treatments}

Primary rat brain microvascular endothelial cells (RBMECs) were isolated and cultured as described previously (Scott et al., 1993). RBMECs were maintained in a hypoxic chamber with a gas mixture containing $94 \% \mathrm{~N}_{2}$ and $5 \% \mathrm{CO}_{2}$. Under these conditions, the $\mathrm{O}_{2}$ level is $2 \pm 1 \%$ in the medium. RBMECs were pretreated with a series of Sal A concentrations $(10,20$, and $100 \mu \mathrm{M})$ for $24 \mathrm{~h}$ and then stimulated with hypoxia for $12 \mathrm{~h}$.

\subsubsection{Measurement of TEER}

The TEER values of RBMECs cultured on 24-well transwell filters were examined by a resistance meter (Millicell ERS-2, Millipore, USA). The TEER values were 
calculated as ohms per square centimeter $\left[\Omega \cdot \mathrm{cm}^{2}, \mathrm{R}_{\text {cell }}\right.$ monolayer $=\left(\mathrm{R}_{\text {sample }}-\mathrm{R}_{\text {blank }}\right) \times$ $0.6]$, according to the surface area of the transwell insert.

\subsubsection{Cell Transfection of MicroRNA-101}

MiR-101 agomir or antagomir were synthesized by GenePharma based on mature miRNA sequences of Rno-miR-101. Cells were transfected using Lipofectamine 3000 (Invitrogen, Thermo Fisher, USA), according to the manufacturer's instruction.

\subsubsection{Quantitative Real-time PCR}

Total RNA was extracted from cells with Trizol reagent (invitrogen, Thermo Fisher, USA). For measuring miR-101, RNA samples were reverse transcribed using Taqman MicroRNA Reverse Transcription Kit, and real-time PCR analysis was performed using Taqman Universal Master Mix II with the TaqMan MicroRNA Assay of miR-101 and U6 (invitrogen, Thermo Fisher, USA). For quantification of the Cul3 mRNA level, Total RNA were extracted with the TaKaRa MiniBEST Universal RNA Extraction Kit (TaKaRa Biotechnology), reverse transcription was performed by HiScript ${ }^{\circledR I I}$ Q Select RT SuperMix for qPCR (+gDNA wiper) (vazyme) and real-time PCR were performed using AceQ ${ }^{\circledR}$ qPCR SYBR ${ }^{\circledR}$ Green Master Mix (vazyme). Relative expression values were calculated using the relative quantification $\left(2^{-\Delta \Delta C t}\right)$ method.

\subsubsection{Luciferase assay}

The pmirGLO vectors (Promega, USA) constructed with either 3'-UTR fragments or mutation of 3'-UTR fragments of Cul3, and antagomiR-101 or agomiR-101 were cotransfected into HEK 293 T cells using Lipofectamine 3000. Luciferase activity was assayed using a luciferase assay system. And the ratio of firefly luciferase activity to renilla luciferase activity represent the relative luciferase activity.

\subsection{Statistical analysis}

The results are presented as the mean \pm SD. One-way analyses of variance (ANOVA) and post hoc comparisons (Bonferroni test) were applied to analyze the difference among groups. And $P<0.05$ was considered statistically significant. 


\section{Acknowledgments}

This work was supported by National Science Fundation of China, No. 81272074, 81471854, 81471853 and 81541043; National Science Fundation of Liaoning Provincial science and Technology Department, No. 201602329; Program for Liaoning Excellent Talents in University No. LR2013091. Innovative entrepreneurship training plan of Shenyang Pharmaceutical University.

\section{Disclosure}

The authors confirm that there are no disclosures, no conflicts of interest and no financial supports to declare.

\section{Reference}

Ai F, Chen M, Li W, Yang Y, Xu G, Gui F, Liu Z, Bai X, Chen Z. 2015. Danshen improves damaged cardiac angiogenesis and cardiac function induced by myocardial infarction by modulating HIF1 $\alpha$ /VEGFA signaling pathway. Int J Clin Exp Med. 8(10):18311-8.

Appelboom G, Detappe A, LoPresti M, Kunjachan S, Mitrasinovic S, Goldman S, Chang SD, Tillement O. 2016. Stereotactic modulation of blood-brain barrier permeability to enhance drug delivery. Neuro Oncol. pii: now137.

Basso DM, Beattie MS, Bresnahan JC. 1995. A sensitive and reliable locomotor rating scale for open field testing in rats. J Neurotrauma. 12(1):1-21.

Bartanusz V, Jezova D, Alajajian B, Digicaylioglu M. 2011.The blood-spinal cord barrier: morphology and clinical implications. Ann Neurol.70(2):194-206.

Echeverry S, Shi XQ, Rivest S, Zhang J. 2011.Peripheral nerve injury alters blood-spinal cord barrier functional and molecular integrity through a selective inflammatory pathway. J Neurosci. 31(30):10819-28.

Emanuele MJ, Elia AE, Xu Q, Thoma CR, Izhar L, Leng Y, Guo A, Chen YN, Rush J, Hsu PW, Yen HC, Elledge SJ. 2011. Global identification of modular cullin-RING ligase substrates. Cell. 147(2):459-74

Fan ZK, Lv G, Wang YF, Li G, Yu DS, Wang YS, Zhang YQ, Mei XF, Cao Y. 2013.The protective effect of salvianolic acid B on blood-spinal cord barrier after compression spinal cord injury in rats. J Mol Neurosci. 51(3):986-93.

Figley SA, Khosravi R, Legasto JM, Tseng YF, Fehlings MG. 2014.Characterization of vascular 
disruption and blood-spinal cord barrier permeability following traumatic spinal cord injury. $\mathrm{J}$ Neurotrauma. 31(6):541-52.

Huang WL, George KJ, Ibba V, Liu MC, Averill S, Quartu M, Hamlyn PJ, Priestley JV. 2007.The characteristics of neuronal injury in a static compression model of spinal cord injury in adult rats. Eur J Neurol. 25:362-72.

Jin Y, Kim HP, Chi M, Ifedigbo E, Ryter SW, Choi AM. 2008.Deletion of caveolin-1 protects against oxidative lung injury via up-regulation of heme oxygenase-1. Am J Respir Cell Mol Biol. 39(2):171-9.

Karginov AV, Tiruppathi C, Malik AB, Minshall RD. 2016.Src-dependent phosphorylation of caveolin-1 Tyr-14 promotes swelling and release of caveolae. Mol Biol Cell. 27(13):2090-106.

Kim JH, Lee KS, Lee DK, Kim J, Kwak SN, Ha KS, Choe J, Won MH, Cho BR, Jeoung D, Lee H, Kumar H, Ropper AE, Lee SH, Han I. 2016.Propitious Therapeutic Modulators to Prevent Blood-Spinal Cord Barrier Disruption in Spinal Cord Injury. Mol Neurobiol. [Epub ahead of print] .

Kwon YG, Kim YM. 2014. Hypoxia-responsive microRNA-101 promotes angiogenesis via heme oxygenase-1/vascular endothelial growth factor axis by targeting cullin 3. Antioxid Redox Signal. 21(18):2469-82

Li W, Jiang D, Li Q, Yao S, Sun X, Yang Y, Meng Z, Liu W. 2016. Lipopolysaccharide-induced preconditioning protects against traumatic spinal cord injury by upregulating Nrf2 expression in rats. Life Sci. 3205(16)30470-2.

Li XQ, Fang B, Tan WF, Wang ZL, Sun XJ, Zhang ZL, Ma H. 2016. miR-320a affects spinal cord edema through negatively regulating aquaporin-1 of blood-spinal cord barrier during bimodal stage after ischemia reperfusion injury in rats. BMC Neurosci. 17:10.

Lin SH, Song W, Cressatti M, Zukor H, Wang E, Schipper HM. 2015. Heme oxygenase-1 modulates microRNA expression in cultured astroglia: implications for chronic brain disorders. Glia. 63(7):1270-84.

Lin LL, Wang W, Cheng MH, Liu AJ. 2012. Protection of different components of Danshen in cerebral infarction in mice. CNS Neurosci Ther. 18(6):511-2.

Loignon M, Miao W, Hu L, Bier A, Bismar TA, Scrivens PJ, Mann K, Basik M, Bouchard A, Fiset PO, Batist Z, Batist G. 2009. Cul3 overexpression depletes Nrf2 in breast cancer and is 
associated with sensitivity to carcinogens, to oxidative stress, and to chemotherapy. Mol Cancer Ther. 8(8):2432-40.

Nag S, Manias JL, Stewart DJ. 2009. Expression of endothelial phosphorylated caveolin-1 is increased in brain injury. Neuropathol Appl Neurobiol. 35(4):417-26.

Oh KS, Oh BK, Mun J, Seo HW, Lee BH. 2011. Salvianolic acid A suppress lipopolysaccharide-induced NF- $\mathrm{BB}$ signaling pathway by targeting IKK $\beta$. Int Immunopharmacol. 11(11):1901-6.

Pamplona A, Ferreira A, Balla J, Jeney V, Balla G, Epiphanio S, Chora A, Rodrigues CD, Gregoire IP, Cunha-Rodrigues M, Portugal S, Soares MP, Mota MM. 2007. Heme oxygenase-1 and carbon monoxide suppress the pathogenesis of experimental cerebral malaria. Nat Med. 13(6):703-10.

Qiang G, Yang X, Xuan Q, Shi L, Zhang H, Chen B, Li X, Zu M, Zhou D, Guo J, Yang H, Zhang L, Du G. 2014. Salvianolic Acid a prevents the pathological progression of hepatic fibrosis in high-fat diet-fed and streptozotocin-induced diabetic rats. Am J Chin Med. 42(5):1183-98.

Scott PA, Bicknell R. 1993. The isolation and culture of microvascular Endothelium. J Cell Sci 105(Pt 2):269-273.

Sharma HS. 2005. Pathophysiology of blood-spinal cord barrier in traumatic injury and repair. Curr Pharm Des. 11(11):1353-89.

Silva N. A., Sousa N., Reis R. L., Salgado A. J. 2014. From basics to clinical: a comprehensive review on spinal cord injury. Progress in Neurobiology. 114:25-57.

Sun Y, Zhu H, Wang J, Liu Z, Bi J. 2009. Isolation and purification of salvianolic acid A and salvianolic acid B from Salvia miltiorrhiza by high-speed counter-current chromatography and comparison of their antioxidant activity. J Chromatogr B Analyt Technol Biomed Life Sci. 877:733-777.

Teng F, Yin Y, Cui Y, Deng Y, Li D, Cho K et al. 2016. Salvianolic acid A inhibits endothelial dysfunction and vascular remodeling in spontaneously hypertensive rats.Life Sci. 144:86-93.

Winkler EA, Sengillo JD, Sagare AP, Zhao Z, Ma Q, Zuniga E, Wang Y, Zhong Z, Sullivan JS, Griffin JH, Cleveland DW, Zlokovic BV. 2014. Blood-spinal cord barrier disruption contributes to early motor-neuron degeneration in ALS-model mice. Proc Natl Acad Sci U S A. 111(11):E1035-42.

Wang YF, Gu YT, Qin GH, Zhong L, Meng YN. 2013. Curcumin ameliorates the permeability of 
the blood-brain barrier during hypoxia by upregulating heme oxygenase-1 expression in brain microvascular endothelial cells. J Mol Neurosci. 51(2):344-51.

Wang SB, Pang XB, Zhao Y, Wang YH, Zhang L, Yang XY, Fang LH, Du GH. 2012. Protection of salvianolic acid A on rat brain from ischemic damage via soluble epoxide hydrolase inhibition. $\mathrm{J}$ Asian Nat Prod Res. 14(11):1084-92.

Wang H, Li X, Zhang W, Liu Y, Wang S, Liu X, He H. 2016. Mechanism-based pharmacokinetic-pharmacodynamic modeling of salvianolic acid A effects on plasma xanthine oxidase activity and uric acid levels in acute myocardial infarction rats. Xenobiotica. 11:1-9.

Xie P, Duan Y, Guo X, Hu L, Yu M. 2015. SalA attenuates hypoxia-induced endothelial endoplasmic reticulum stress and apoptosis via down-regulation of VLDL receptor expression. Cell Physiol Biochem. 35(1):17-28.

Yang MC, Zhang HZ, Wang Z, You FL, Wang YF. 2016. The molecular mechanism and effect of cannabinoid-2 receptor agonist on the blood-spinal cord barrier permeability induced by ischemia-reperfusion injury. Brain Res. 1636:81-92.

Zhou Y, Zhang H, Zheng B, Ye L, Zhu S, Johnson NR, Wang Z, Wei X, Chen D, Cao G, Fu X, Li X, Xu HZ, Xiao J. 2016. Retinoic Acid Induced-Autophagic Flux Inhibits ER-Stress Dependent Apoptosis and Prevents Disruption of Blood-Spinal Cord Barrier after Spinal Cord Injury. Int J Biol Sci. 12(1):87-99.

Zhang Q, Yang H, An J, Zhang R, Chen B, Hao DJ. 2016. Therapeutic Effects of Traditional Chinese Medicine on Spinal Cord Injury: A Promising Supplementary Treatment in Future. Evid Based Complement Alternat Med. 2016:8958721.

Zhong R, Xiao J, Yu Z, Zhou J, Dai C. 2015. Research on the effect of protection against ventilator-induced lung injury via regulation of caveolin-1/heme oxygenase-1 signaling. Zhonghua Wei Zhong Bing Ji Jiu Yi Xue. 27(7):568-73.

Zimnicka AM, Husain YS, Shajahan AN, Sverdlov M, Chaga O, Chen Z, Toth PT, Klomp J, Zeng M, Pan L, Qi S, Cao Y, Zhu H, Guo L, Zhou J. 2013. Systematic review of recent advances in pharmacokinetics of four classical Chinese medicines used for the treatment of cerebrovascular disease. Fitoterapia. 88:50-75. 
Fig. 1 The permeability of Blood-spinal cord barrier was assessed by Evans Blue extravasation ( $\mu \mathrm{g} / \mathrm{g}$ spinal cord tissue) in $\mathrm{SCl}$ group, $\mathrm{SCl}+\mathrm{Sal} \mathrm{A}$ group $(2.5,5$ and 10 $\mathrm{mg} / \mathrm{kg}$, i.p.) and $\mathrm{SCl}+\mathrm{Sal} \mathrm{A}+\mathrm{Znpp}$ group. Data present means \pm S.D. ( $n=7$, each). ${ }^{\star} P<$ 0.05 vs.SCl group. ${ }^{\#} P<0.05$ vs. SCI + Sal A group.

Fig. 2 Effects of Sal A on ZO-1 and Claudin-5 protein in the injured spinal cord site at 24 hr after SCl. Lane 1: sham-operated group; lane 2: SCl group; lane 3: $\mathrm{SCl}+\mathrm{Sal} \mathrm{A}$ group; lane 4: $\mathrm{SCl}+\mathrm{Sal} \mathrm{A}+\mathrm{Znpp}$ group. (A) Representative Western blots illustrating differences in ZO-1 and Claudin-5. Relative integrated density value (IDV) analysis of $p-C a v e o l i n-1(B)$, ZO-1 (C) and Claudin-5 protein (D) ( $n=7$, each). ${ }^{* *} P<0.01$ vs. sham-operated group. ${ }^{\# \#} P<$ 0.01 vs. SCl group. ${ }^{* \#} P<0.01$ vs. $\mathrm{SCl}+$ Sal A group.

Fig. 3 Effects of Sal A on HO-1 protein in the injured spinal cord site at $24 \mathrm{hr}$ after SCl. Lane 1: sham-operated group; lane 2: $\mathrm{SCl}$ group; lane 3: $\mathrm{SCl}+\mathrm{Sal} \mathrm{A}$ group; lane 4: $\mathrm{SCl}+\mathrm{Sal} \mathrm{A}+\mathrm{Znpp}$ group. (A) Representative Western blots illustrating differences in HO-1. (B) Relative integrated density value (IDV) analysis of HO-1 protein ( $n=7$, each). ${ }^{* \star} P<$ 0.01 vs. sham-operated group. ${ }^{* \#} P<0.01$ vs. $\mathrm{SCl}+$ Sal A group.

Fig. 4 Effects of Sal A on caspase-3, Bcl-2 and Bax protein in the injured spinal cord site at $24 \mathrm{hr}$ after SCl. Lane 1: sham-operated group; lane 2: SCl group; lane 3: $\mathrm{SCl}+\mathrm{Sal} \mathrm{A}$ group; lane 4: $\mathrm{SCl}+\mathrm{Sal} \mathrm{A}+\mathrm{Znpp}$ group. (A) Representative Western blots illustrating differences in caspase-3, Bcl-2 and Bax. Relative integrated density value (IDV) analysis of caspase-3 (B), Bcl-2 (C) and Bax (D) protein ( $n=7$, each). ${ }^{* *} P<0.01$ vs. sham-operated group. ${ }^{\# \#} P<0.01$ vs. SCl group. ${ }^{* \#} P<0.05$ vs. SCl+Sal A group.

Fig. 5 Effects of Sal A on Bax and Bcl-2 protein in the gray matter of the spinal cord site at $24 \mathrm{hr}$ after $\mathrm{SCl}$ by immunohistochemical method. A1,B1: sham-operated group; A2,B2: SCI group; $\mathrm{A} 3, \mathrm{~B} 3: \mathrm{SCl}+\mathrm{Sal}$ A group; $\mathrm{A} 4, \mathrm{~B} 4: \mathrm{SCl}+\mathrm{Sal} \mathrm{A}+\mathrm{Znpp}$ group. Mean Optical density value (IDV) analysis of $\mathrm{Bcl}-2$ (C) and Bax protein (D) ( $n=6$, each). ${ }^{*} P<0.05$ vs. sham-operated group. ${ }^{\#} P<0.05$ vs. SCl group. ${ }^{*} P<0.05$ vs. $\mathrm{SCl}+$ Sal A group. Scale bar: $50 \mu \mathrm{m}$.

Fig.6 Effect of Sal A on motor function was assessed using the BBB scoring system up to $21 \mathrm{~d}$ after $\mathrm{SCl}\left(n=7\right.$, each). ${ }^{*} P<0.05,{ }^{* *} P<0.01$ vs. SCI group. ${ }^{\#} P<0.05,{ }^{\# \#} P<0.05$ vs. $\mathrm{SCl}+\mathrm{Sal} \mathrm{A}$ group. 
Fig.7 Effect of Sal A and miR-101 on the permeability of RBMECs induced by hypoxia.A: Effect of Sal $A$ on the permeability of RBMECs induced by hypoxia. ${ }^{*} P<0.05$ vs. Control group. B. The TEER in RBMECs in different group. ${ }^{*} P<0.05$ vs. Control group; ${ }^{\#} P<0.05$ vs. Sal A+MiR-101 (-)-NC group. ${ }^{*} P<0.05$ vs. Sal A+MiR-101 (+)-NC group.

Fig.8 The role and mechanism of miR-101 in the rat brain microvascular endothelial cells (RBMECs). A.The expression of miR-101 in different group. ${ }^{* *} P<0.01$ vs. Control group. B. MiRNA-101 inhibits the expression of Cul3 by targeting its 3'-untranslated region. Data represent means $\pm \operatorname{SD}\left(\mathrm{n}=5\right.$, each). ${ }^{* *} P<0.01$ versus MiR-101(+)-NC-wt group; ${ }^{\# \#} P<0.01$ vs. MiR-101(+)-wt group; C:The relative expression of Cul3 mRNA in different group. D :The expression of Cul3 protein in different group and the integrated density value(E). ${ }^{* \star} P<0.01$ versus MiR-101(-)-NC group, ${ }^{\#} P<0.05$ vs. MiR-101(+)-NC group;

Fig.9 F:The effect of miR-101 on the expression of HO-1 and Nrf2 protein in different group. Representative Western blots illustrating differences in HO-1 and Nrf2 protein (A). Relative integrated density value (IDV) analysis of $\mathrm{HO}-1$ (B) and Nrf2 protein(C). ${ }^{* *} P$ $<0.05,{ }^{* *} P<0.01$ vs. MiR-101(-)-NC group, ${ }^{\# \#} P<0.01$ versus MiR-101(+)-NC group. 
A

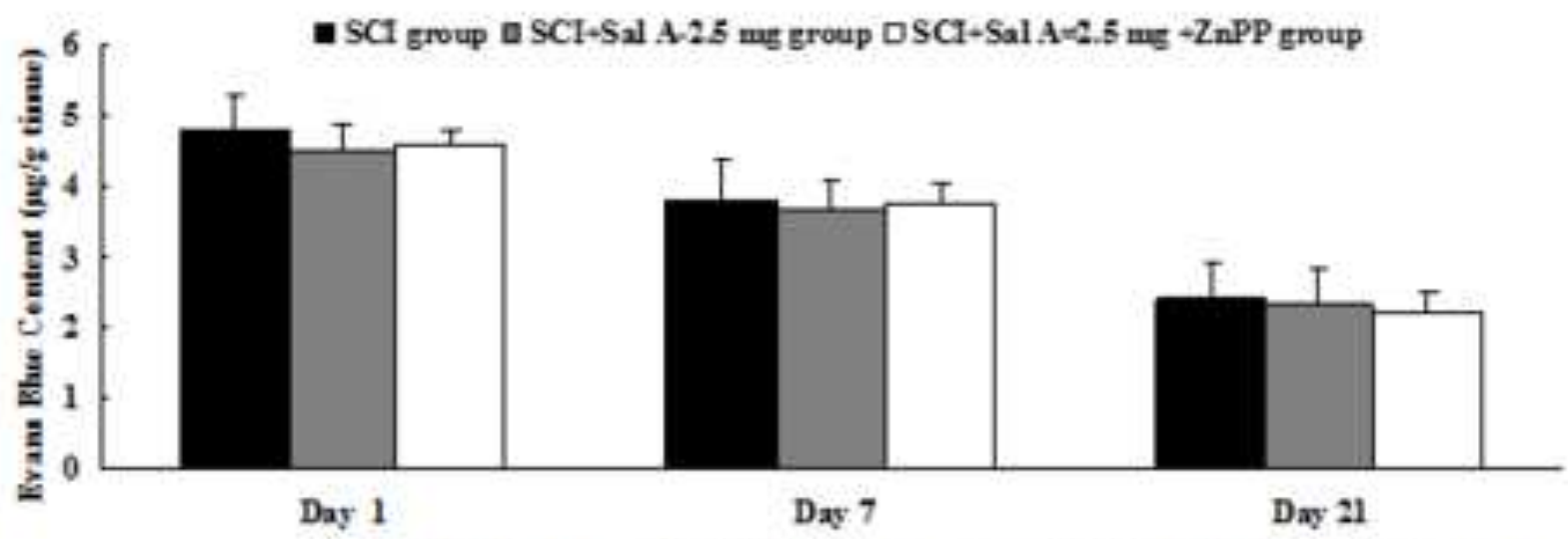

B 6 - 6 SCI group uSCI $+\mathrm{SalA}-5 \mathrm{mg}$ group $\square \mathrm{SCI}+\mathrm{Sal} \mathrm{A-5mg}+\mathrm{ZnPP}$ group

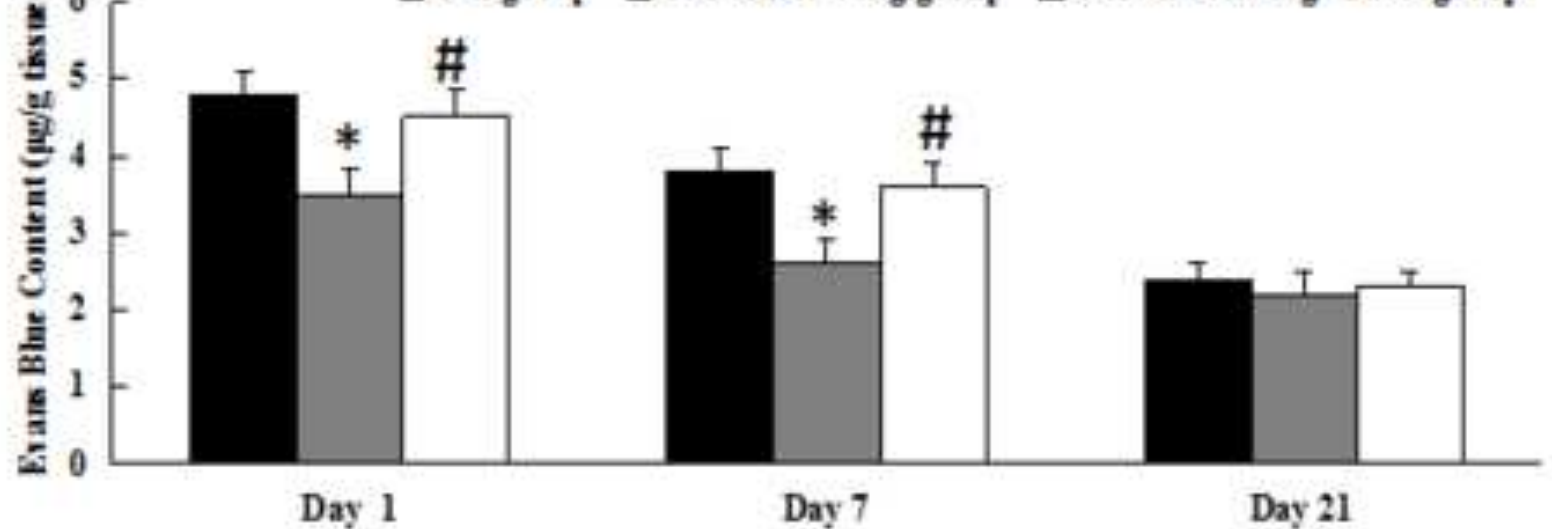

Day 1

Day 7

Day 21

- SCI group $\quad$ SCI + Sal A $10 \mathrm{mg}$ group $\square \mathrm{SCI}+\mathrm{Sal} \mathrm{A}-10 \mathrm{mg}+\mathrm{ZnPP}$ group

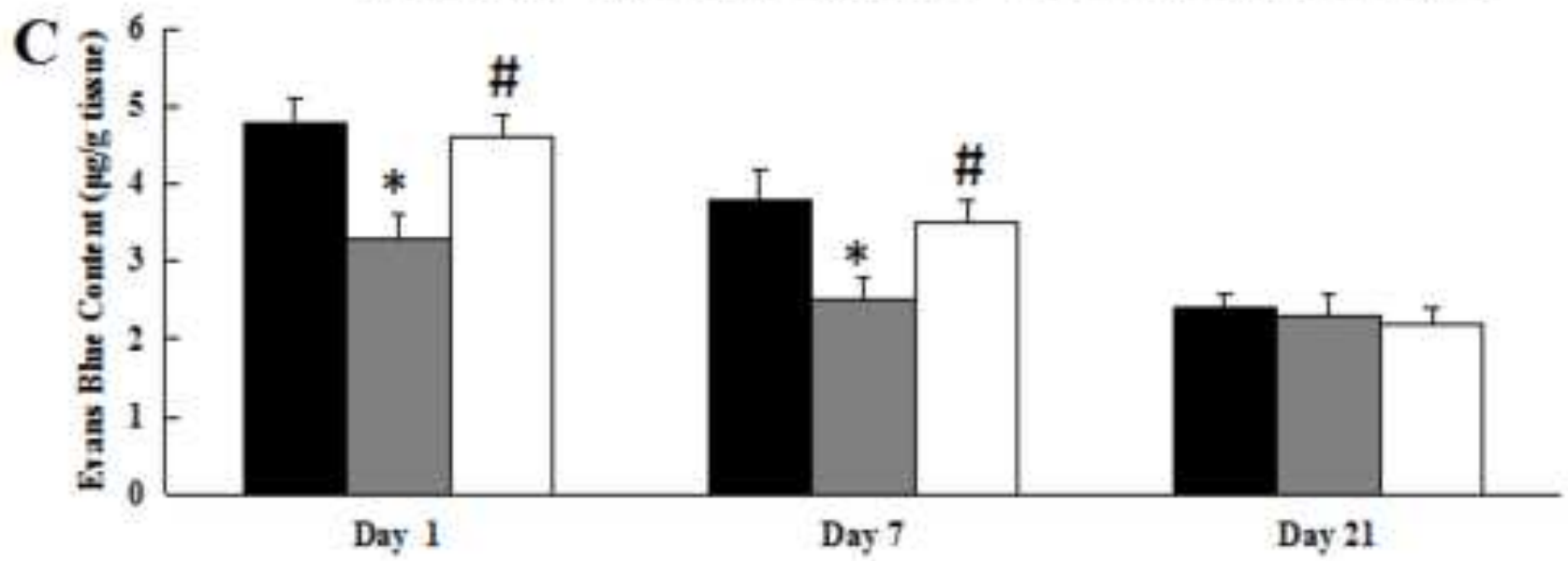




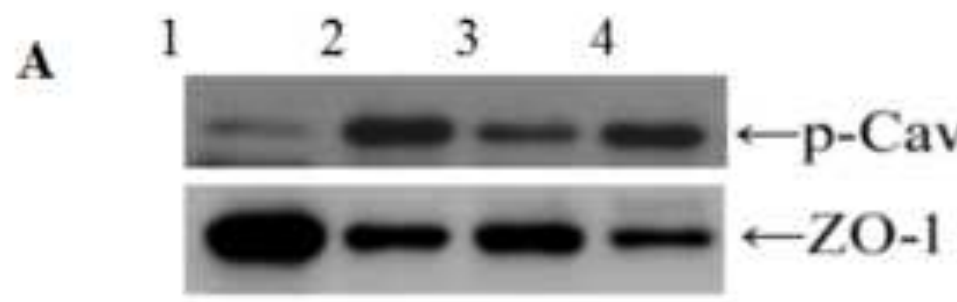

$\omega=0+$ Claudin-5

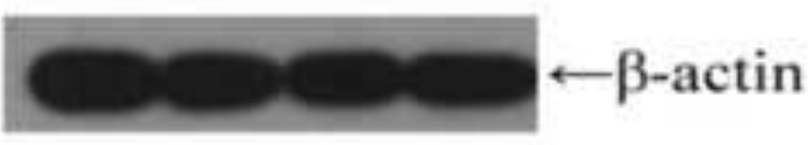

C

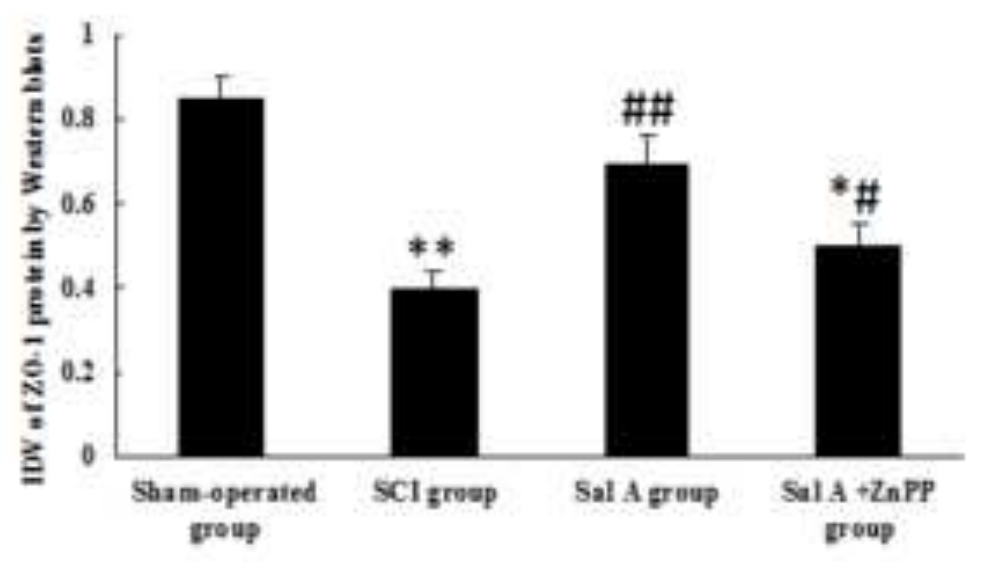

B

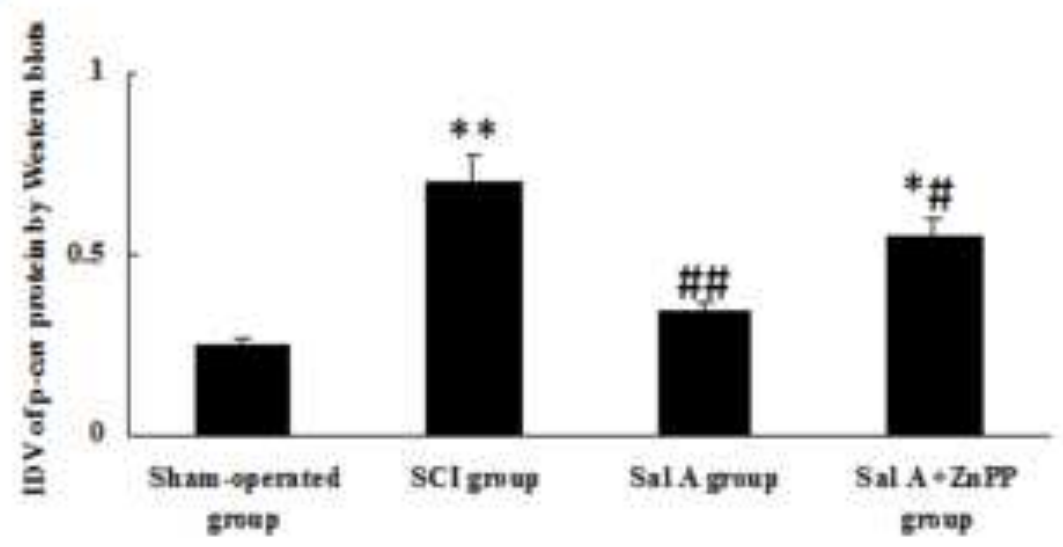

D

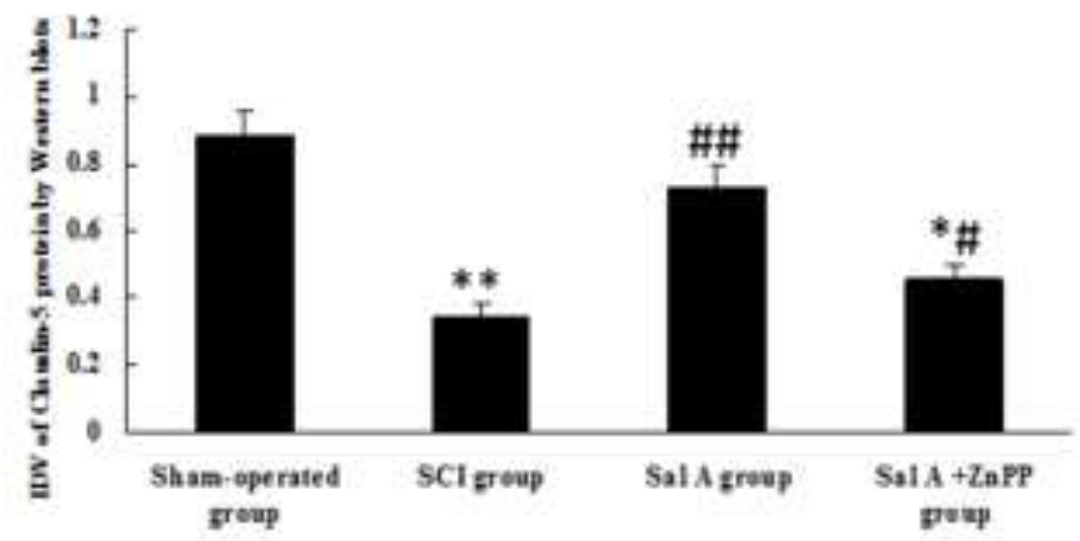




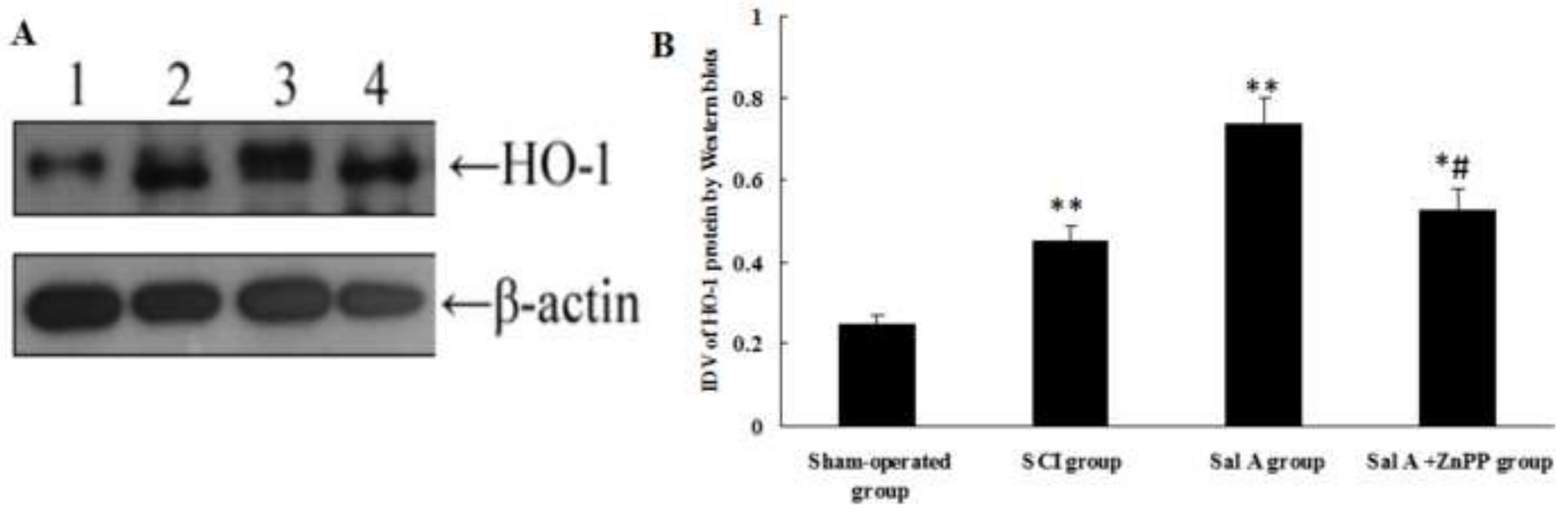


A
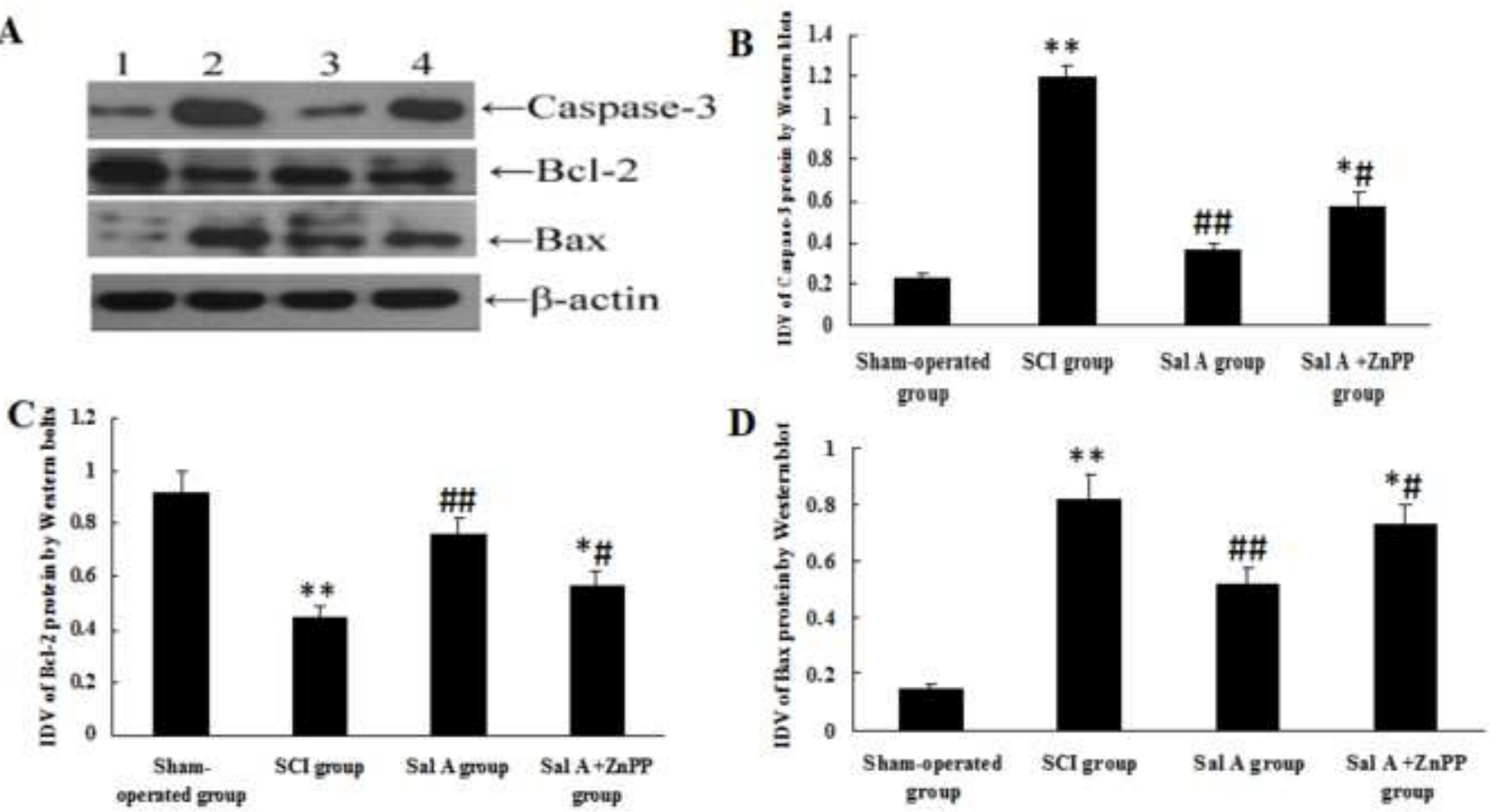

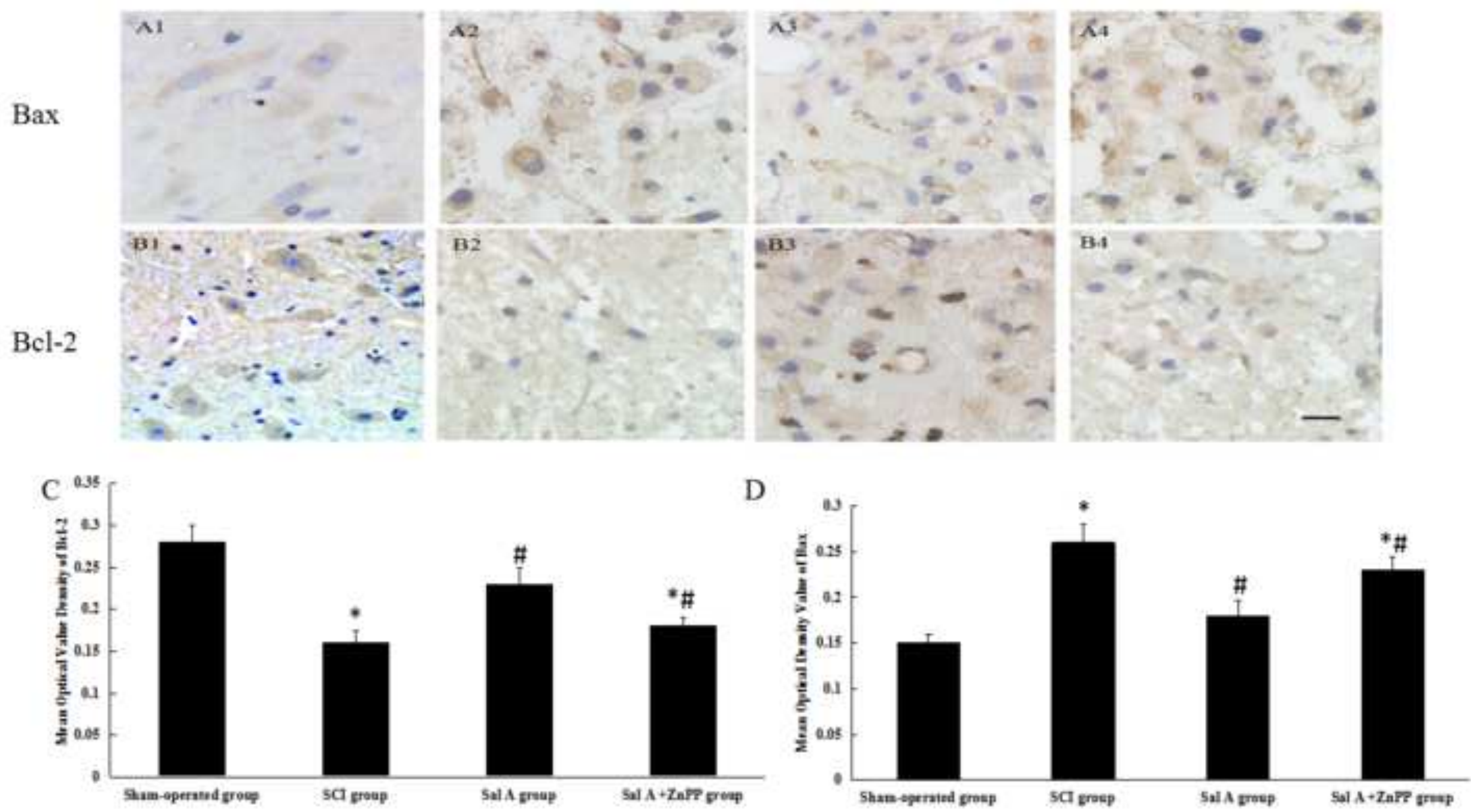


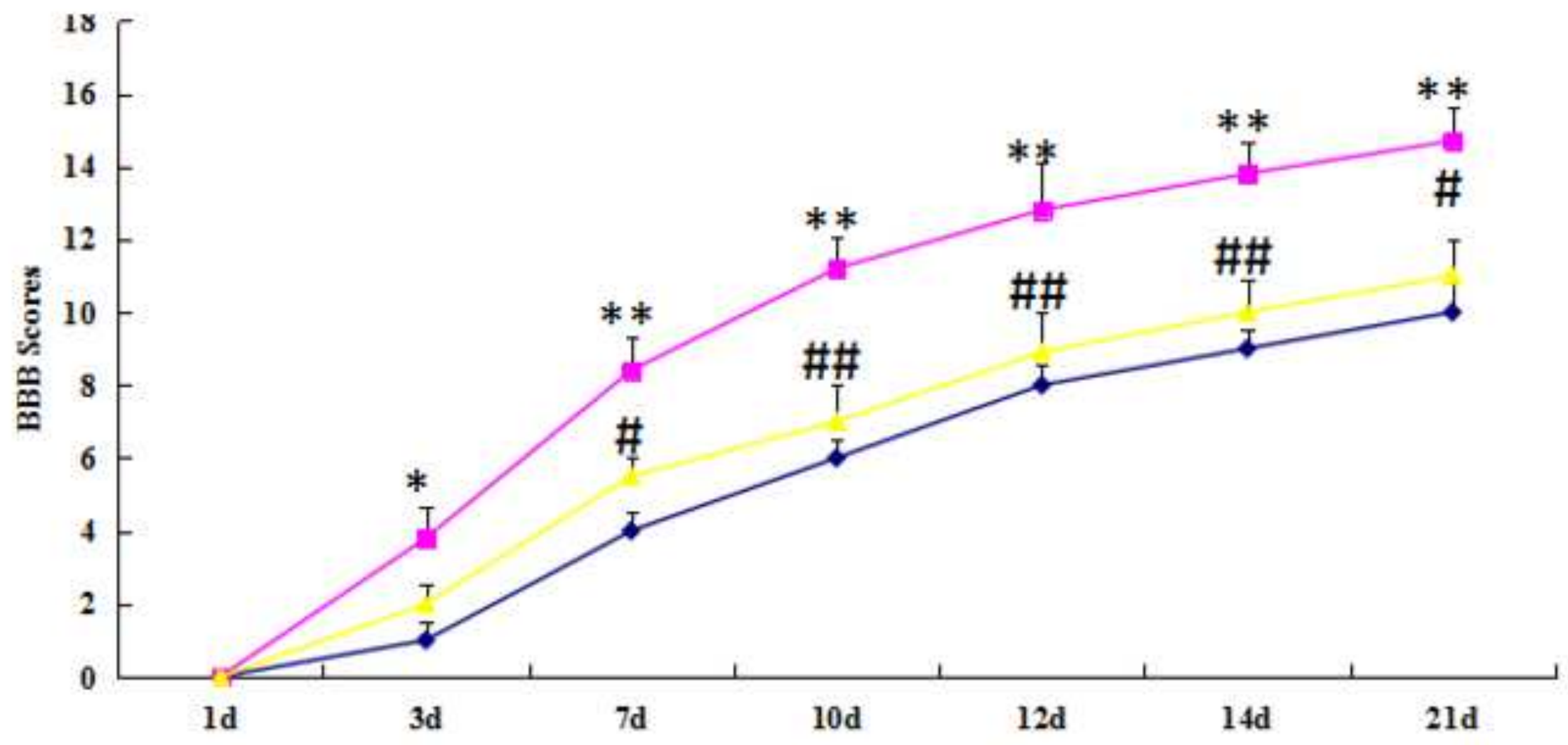

$\bullet-\mathrm{SCI}$ group $\quad-\mathrm{SCI}+\mathrm{Sal} \mathrm{A}$ group $\quad \mathrm{SCI}+\mathrm{Sal} \mathrm{A}+\mathrm{ZnPP}$ group 
A
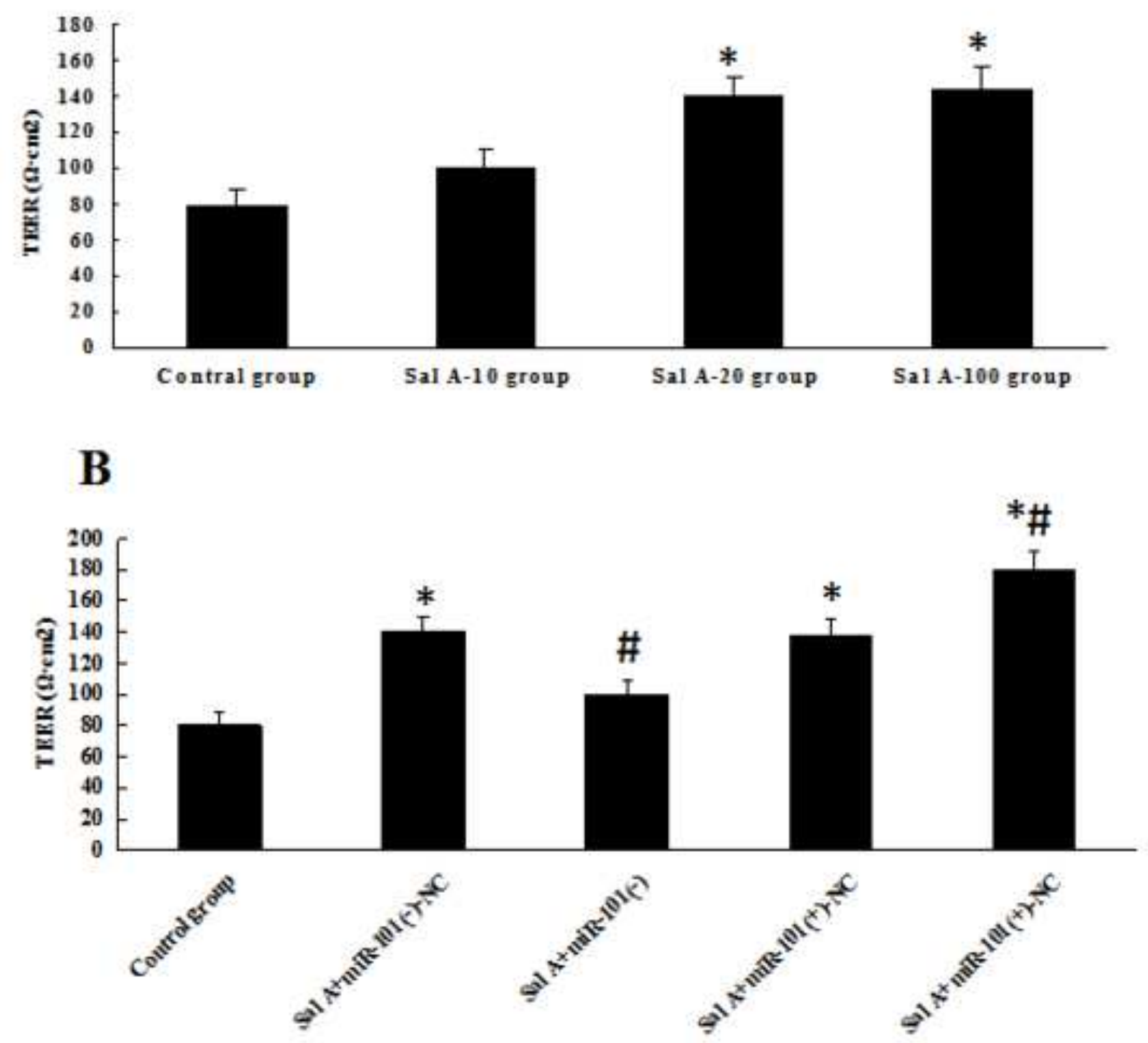
A

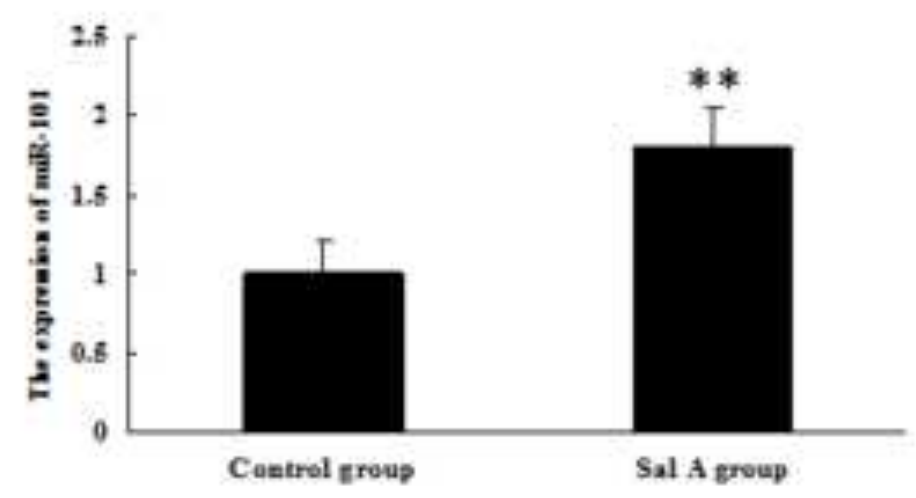

C

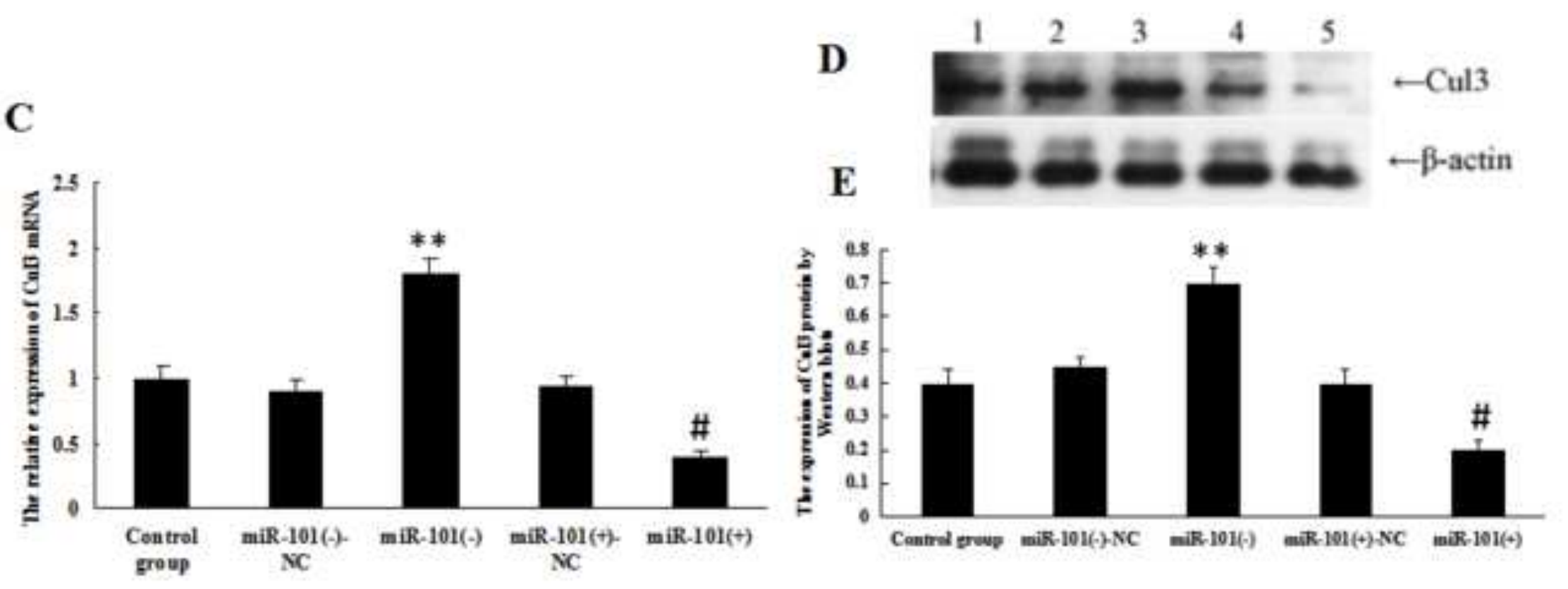

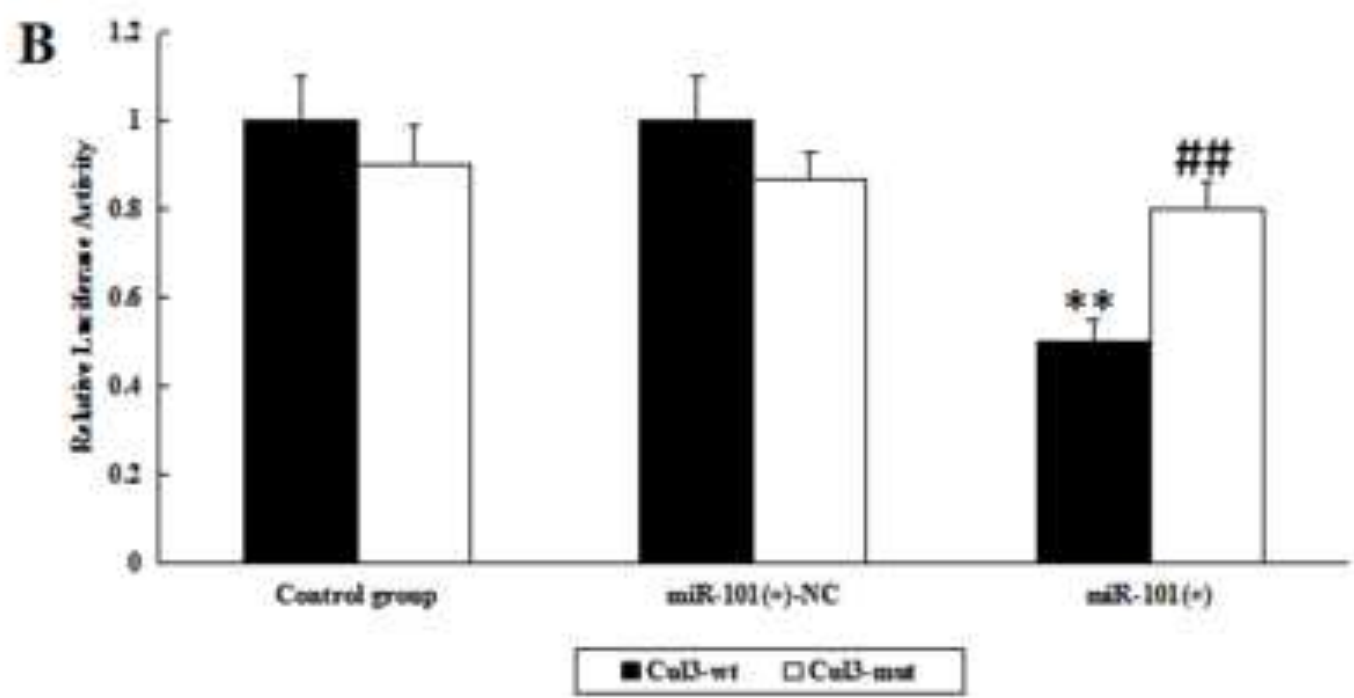
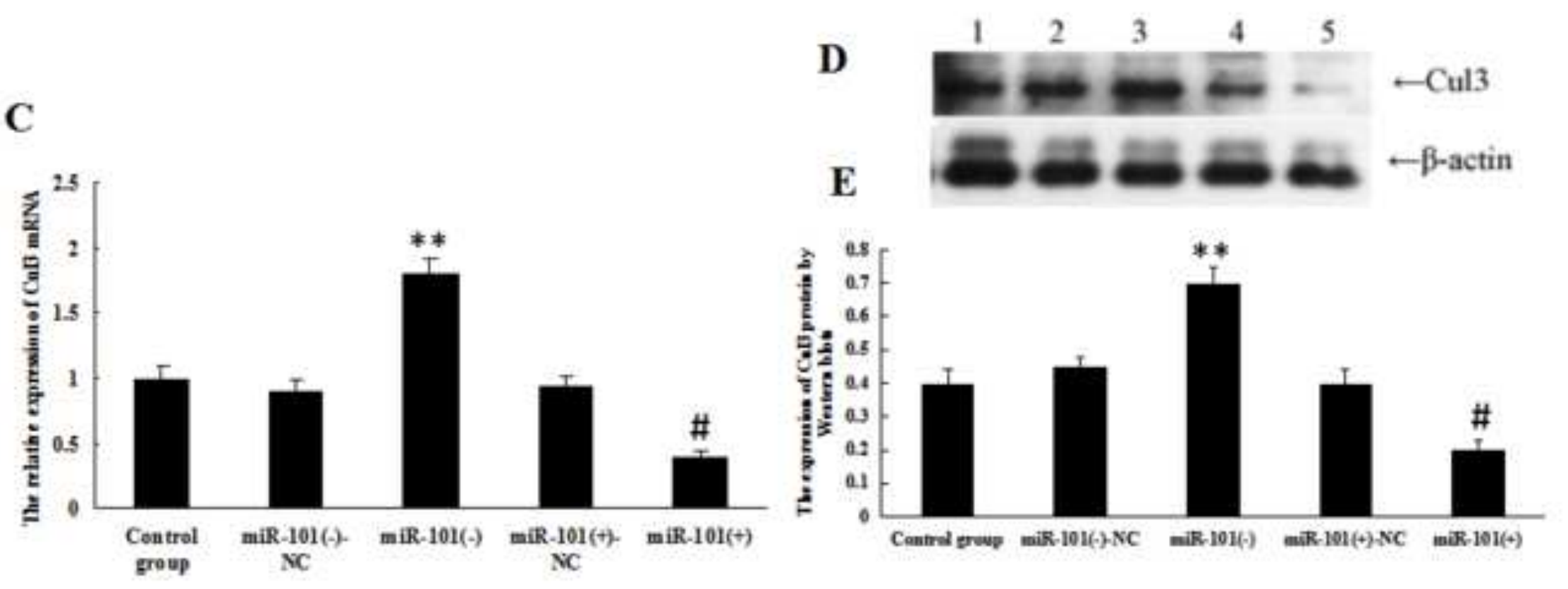
A

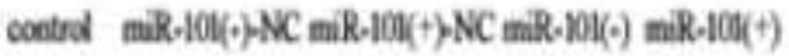

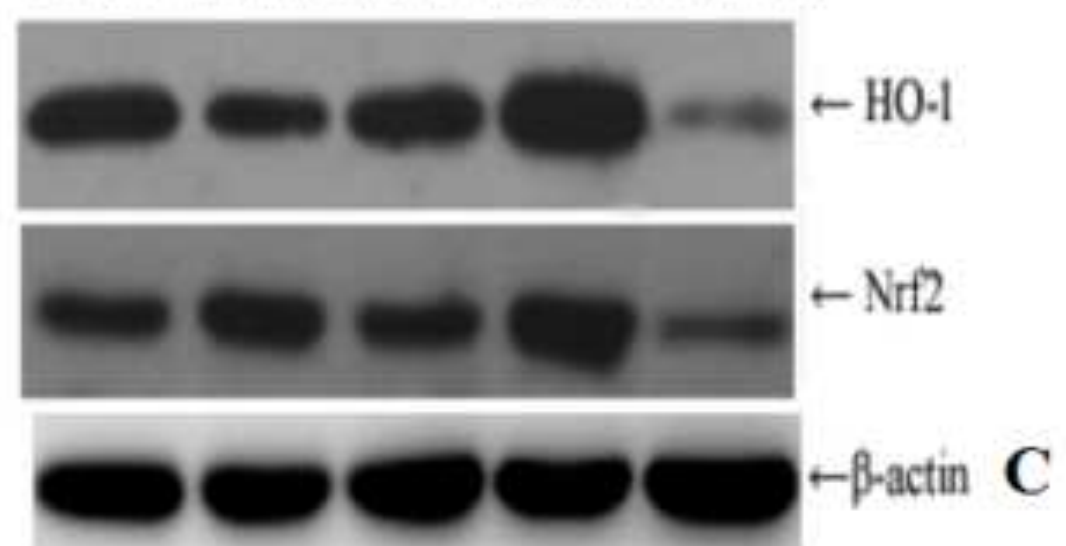

- $-1+\beta$-actin
B
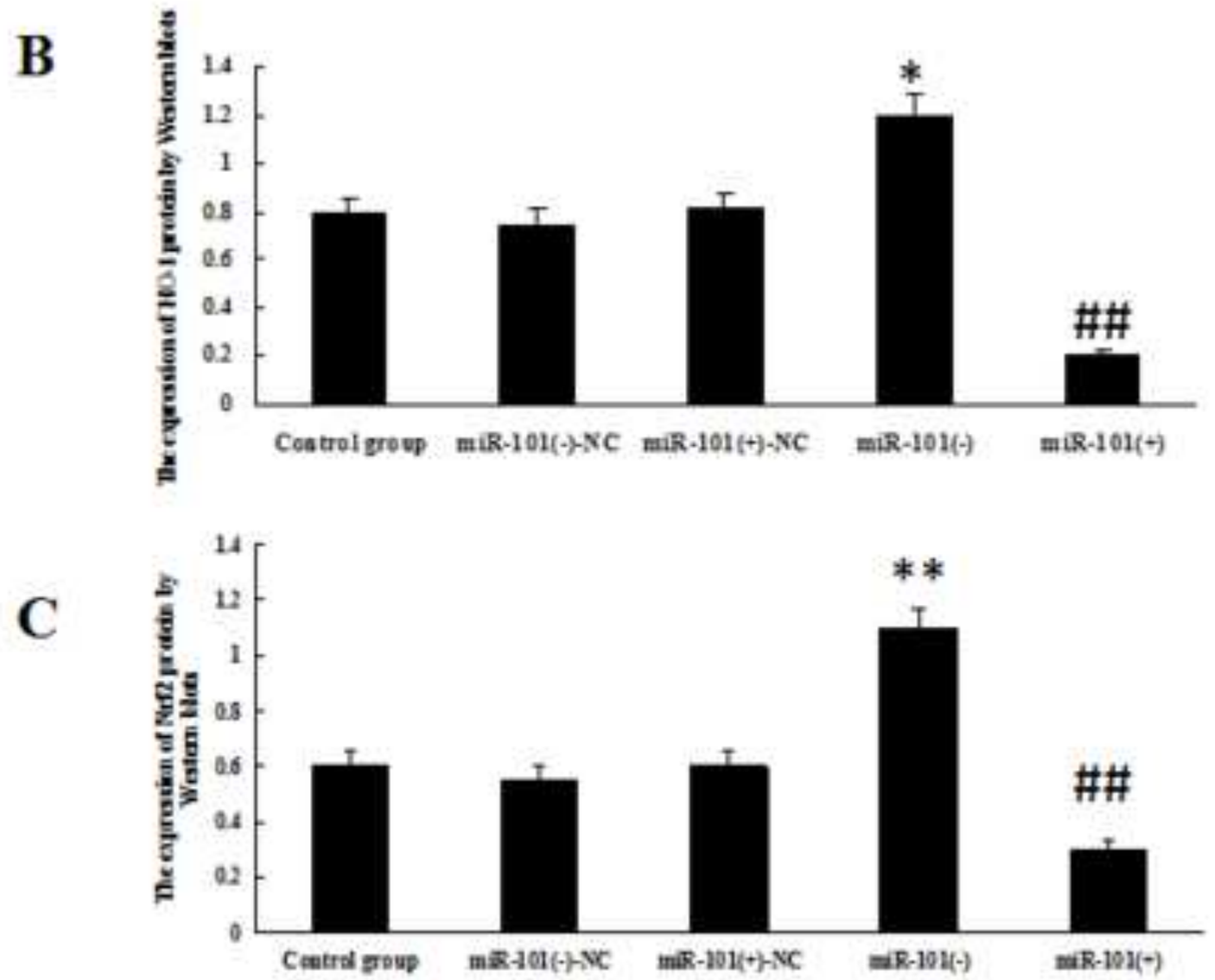